\title{
Long-Lasting Rescue of Age-Associated Deficits in Cognition and the CNS Cholinergic Phenotype by a Partial Agonist Peptidomimetic Ligand of TrkA
}

\author{
Martin A. Bruno, ${ }^{1}$ Paul B. S. Clarke, ${ }^{1}$ Alicia Seltzer, ${ }^{6}$ Rémi Quirion, ${ }^{1,2}$ Kevin Burgess, ${ }^{7}$ A. Claudio Cuello,, $13 \star$ and \\ H. Uri Saragovi ${ }^{1,4,5 *}$ \\ Departments of ${ }^{1}$ Pharmacology and Therapeutics, ${ }^{2}$ Psychiatry/Douglas Hospital Research Center, ${ }^{3}$ Anatomy and Cell Biology, and ${ }^{4}$ Oncology/Cancer \\ Center, and ${ }^{5}$ Lady Davis Research Institute, McGill University, Montréal, Quebec, H3T 1E2 Canada, ${ }^{6}$ Facultad de Medicina, Universidad de Cuyo, Mendoza \\ 5500, Argentina, and 'Department of Chemistry, Texas A\&M University, College Station, Texas 77842
}

Previously, we developed a proteolytically stable small molecule peptidomimetic termed D3 as a selective ligand of the extracellular domain of the TrkA receptor for the NGF. Ex vivo D3 was defined as a selective, partial TrkA agonist. Here, the in vivo efficacy of D3 as a potential therapeutic for cholinergic neurons was tested in cognitively impaired aged rats, and we compared the consequence of partial TrkA activation (D3) versus full TrkA/p75 activation (NGF). We show that in vivo D3 binds to TrkA receptors and affords a significant and long-lived phenotypic rescue of the cholinergic phenotype both in the cortex and in the nucleus basalis. The cholinergic rescue was selective and correlates with a significant improvement of memory/learning in cognitively impaired aged rats. The effects of the synthetic ligand D3 and the natural ligand NGF were comparable. Small, proteolytically stable ligands with selective agonistic activity at a growth factor receptor may have therapeutic potential for neurodegenerative disorders.

Key words: peptidomimetic; age; cognition; memory; TrkA; NGF; agonist; cholinergic; CNS

\section{Introduction}

Neurotrophins are growth factors that regulate the development and maintenance of the peripheral and the central nervous systems (Lewin and Barde, 1996; Saragovi and Burgess, 1999). Neurotrophins and their receptors are targets for therapeutic intervention in neurodegeneration (Eide et al., 1993; Hefti, 1994; Thoenen, 1995; Saragovi and Burgess, 1999; Saragovi and Gehring, 2000).

The neurotrophin nerve growth factor (NGF) acts by binding to receptors TrkA and p75. NGF-TrkA binding (approximate $K_{\mathrm{d}}$, $10^{-11} \mathrm{M}$ ) activates the intrinsic tyrosine kinase of the receptor, causing tyrosine phosphorylation of TrkA and associated signaling partners, and activates "traditional" neurotrophic biological signals. These signals promote cell survival or differentiation (Kaplan and Miller, 2000). The p75 receptor is a member of the tumor necrosis factor receptor superfamily. Depending on the cellular environment and the type of ligand, p75 can transduce pro-survival, pro-apoptotic, or pro-differentiation signals

Received June 25, 2003; revised July 29, 2004; accepted Aug. 3, 2004.

This work was supported by Canadian Institutes of Health Research Grants MT-13265 (H.U.S.) and MOP 62735 (A.C.C.) and National Institutes of Health Grant CA82642 (K.B.). M.A.B. received a fellowship from Consejo Nacional de Investigaciones Científicas y Técnicas, Argentina. We thank Dr. H. Nedev and M. C. Zaccaro (McGill University, Montreal, Quebec, Canada) for aid with compound synthesis and characterization and K. Bell and E. Tsang for aid with image analysis and histology.

${ }^{*}$ A.C.C. and H.U.S. contributed equally to this work.

Correspondence should be addressed to Dr. H. Uri Saragovi, Lady Davis Institute-Jewish General Hospital, 3755 Cote St. Catherine, F-223, Montreal, Quebec, H3T 1E2 Canada. E-mail: Uri@pharma.mcgill.ca.

DOI:10.1523/JNEUROSCI.1508-04.2004

Copyright $\odot 2004$ Society for Neuroscience $\quad$ 0270-6474/04/248009-10\$15.00/0
(Barker, 1998; Rabizadeh et al., 1999; Zaccaro et al., 2001; Saragovi and Zaccaro, 2002). These features make p75 biology complex and the behavior of p75 ligands unpredictable.

Mature cholinergic basal forebrain (CBF) neurons, which innervate the cerebral cortex and hippocampus, play a key role in cognition and memory (Lad et al., 2003). These neurons express NGF receptors (Backman et al., 1997) and are dependent for their health and cholinergic phenotype on NGF receptor activation (Debeir et al., 1999; Sofroniew et al., 2001). In aging and cognitive disorders such as Alzheimer's disease (AD), CBF neurons undergo atrophy and eventually degenerate (Turrini et al., 2001; Casu et al., 2002). This process correlates with a progressive reduction of TrkA density before cellular death (Mufson et al., 1997, 2000; Sendera et al., 2000). Indeed, TrkA (but not of p75) depletion is a reliable marker of progressively deteriorating cognitive ability (Counts et al., 2004). Thus, exogenous NGF has been used as an experimental therapeutic agent in aging and stroke animal models (Garofalo et al., 1992; Backman et al., 1997; Frick et al., 1997) and in human AD patients (Gage et al., 1988). Exogenous NGF reversed the age-dependent changes in $\mathrm{CBF}$ neurons and improved performance in spatial memory tasks. The effect of NGF was long-lived after discontinuation of delivery. However, NGF therapy for AD patients failed because of CNS delivery problems and pleiotropic and adverse side effects (Barinaga, 1994; Verrall, 1994; Jonhagen, 2000). Moreover, it is hard to interpret the outcome of NGF-p75 interactions in vivo in the aged brain.

We reasoned that it would be advantageous to apply ligands 
that bind TrkA and exclude p75. To this end, we developed a TrkA-selective NGF peptidomimetic termed D3. D3 induces TrkA tyrosine phosphorylation, stabilizes TrkA-TrkA homodimers, enhances ChAT production/activity, and induces neurotrophic activities in PC12 cells and primary neuronal cultures (Maliartchouk et al., 2000). D3 has partial agonistic activity but could be best described as a potentiator of NGF action. In addition, D3 is a small (mass, $580 \mathrm{Da}$ ), water-soluble and proteolytically stable molecule. In view of these drug-like features, we tested whether D3 has superior in vivo pharmacological properties compared with the NGF polypeptide.

\section{Materials and Methods}

\section{Animals}

Aged (24 months old) and young (6 months old) male Fisher-344 rats were used. Efforts were made to minimize the number of animals used and their suffering. All procedures were approved beforehand by the Animal Care Committee of McGill University and followed the guidelines of the Canadian Institutes of Health Research.

\section{D3 distribution in brain}

D3 and its analog D3-biotin (D3 conjugated with biotin) bind TrkA with similar properties (Maliartchouk et al., 2000), and D3-biotin can be followed via the biotin label (Maliartchouk et al., 2000). To assess whether D3 can diffuse when given intracerebroventricularly, male Fischer-344 aged rats $(n=2)$ were anesthetized, placed in a stereotaxic apparatus, and given a single injection of D3-biotin. A relatively high dose of D3-biotin (10 $\mu \mathrm{g}$ in $10 \mu \mathrm{l}$ ) was used because our pilot studies (data not shown) demonstrated it yields a good signal in these diffusion studies. D3-biotin was injected into the lateral ventricle (anteroposterior, $-0.8 \mathrm{~mm}$; lateral, $1.3 \mathrm{~mm}$; vertical, $3.5 \mathrm{~mm}$ ) (Paxinos and Watson, 1986). Without perfusion (to avoid washout during perfusion-fixation), rats were killed after an intracerebroventricular injection at $0.25,2,4,8,12$, and $24 \mathrm{hr}$. Fixed ( $4 \%$ paraformaldehyde; $15 \mathrm{~min}$ ), free-floating sections $(50 \mu \mathrm{m})$ were cut using a freezing sledge microtome, followed by $30 \mathrm{~min}$ of blocking with $3 \%$ normal mouse serum (Chemicon, Temecula, CA). After rinsing, sections were incubated at room temperature for $2 \mathrm{hr}$ with a mouse IgG anti-biotin-Alexa-488 (1:300; Molecular Probes, Eugene, OR). Sections were rinsed three times with PBS and then mounted onto gelatin-coated slides using Vectashield mounting medium for fluorescence (Vector Laboratories, Burlingame, CA).

\section{Cellular distribution and D3-TrkA localization studies}

Aged rats $(n=4)$ received a single intracerebroventricular injection of D3-biotin $(1 \mu \mathrm{g}$ in $10 \mu \mathrm{l})$, and $24 \mathrm{hr}$ later, their brains were perfusedfixed ( $24 \mathrm{hr}$ because the biodistribution studies above indicated good penetration). Then, $35-\mu \mathrm{m}$-thick sections containing the nucleus basalis and cerebral cortex regions were prepared, and double immunostaining was done to identify neurons, glia, or TrkA receptors. Neurons were identified with mouse anti-neural nuclei (NeuN) antibody (1:100; Chemicon), followed by goat anti-mouse coupled with rhodamine (1: 100; red; Jackson ImmunoResearch, West Grove, PA), and D3-biotin on neurons was identified with goat anti-biotin-FITC (green; Sigma, St. Louis, MO). Glia were identified using mouse anti-glial fibrillary acidic protein (GFAP; 1:100; Chemicon), followed by goat anti-mouse coupled with rhodamine (1:100; red; Jackson ImmunoResearch), and D3-biotin on glia was identified with goat anti-biotin-FITC (green; Sigma). TrkA receptors were identified using rabbit anti-TrkA antibody (1:500; Chemicon), followed by donkey anti-rabbit coupled with rhodamine red $\mathrm{X}$ (1:100; red; Jackson ImmunoResearch), and D3-biotin colocalizing with TrkA was identified with mouse IgG anti-biotin-Alexa-488 (1:300; green; Molecular Probes). In all cases, sections were preincubated and blocked with the corresponding normal serum secondary antibody. The colocalization of D3-biotin and neuronal, glial, or TrkA markers was examined with an LSM 510 laser scanning confocal microscope (Zeiss, Oberkochen, Germany).

\section{Behavioral task}

We resorted to segregating animals in spatially cognitively impaired and unimpaired groups applying well accepted protocols using the Morris water maze test (Fischer et al., 1987; Gage et al., 1988; Chen et al., 1995), to avoid the potential confounding effects of studying drug effects on a global and heterogeneous population of aged rats.

Acquisition phase. Aged $(n=120)$ and young $(n=10)$ rats were screened for spatial memory deficits using the Morris water maze as described previously (Issa et al., 1990; Aubert et al., 1995). The animals were required to find a submerged platform in a $1.4 \mathrm{~m}$ diameter pool of white, nontoxic colored water using only distal and spatial clues available in the testing room. Throughout, all tests were always carried in the same room and set up. The center of the escape platform ( $15 \mathrm{~cm}$ diameter) was located $45 \mathrm{~cm}$ from the pool wall, in the northeast quadrant. Animals were tested in 15 trials over 5 consecutive days (three trials per day with an intertrial time of $20 \mathrm{~min}$ ) with the platform $2 \mathrm{~cm}$ below the water. At the end of the testing periods, all animals were given three trials in which the platform was raised $2 \mathrm{~cm}$ above the water to exclude visual deficits as the cause of poor performance, as described (Rowe et al., 2003). The swim speeds and distances were recorded using a video tracking system (HVS Image, Buckingham, UK) to exclude motor deficits as the cause of poor performance, as described (Rowe et al., 2003). For excluding thigmotaxis and amotivational status as the cause of poor performance (Graziano et al., 2003; Rowe et al., 2003), concentric zones of the pool defined by the software program (HVS Image) were used to average swim patterns during days $2-5$ of the acquisition phase.

The latency to locate the escape platform was used to segregate rats into aged cognitively unimpaired and aged cognitively impaired groups. Aged rats whose individual mean latencies to locate the platform were within 0.5 SDs of the latency of young rats were considered cognitively unimpaired $(n=19)$. Aged rats whose individual average latencies to locate the platform were $>2$ SDs from those of young rats on days $2-5$ of the acquisition phase were considered cognitively impaired $(n=31)$, as described (Tombaugh et al., 2002; Rowe et al., 2003). Rats displaying an intermediate performance between unimpaired and impaired (i.e., rats with $<2$ SDs but $>0.5$ SDs) were eliminated from this study $(n=70)$ because this "cognitively mildly impaired population" was expected to yield highly variable behavioral data.

Testing phase. Throughout, all tests were always carried in the same room and the same Morris water maze was set up. Aged cognitively impaired rats were treated with saline, NGF, or D3 (see below) during 2 weeks, allowed to recover from surgery for 1 week (week 3 ), and then they were retested in the Morris water maze (week 4) with the platform submerged in the same position as in the acquisition phase. Animals were tested in nine trials over 3 consecutive days (three trials per day with an intertrial time of $20 \mathrm{~min}$ ) with the platform $2 \mathrm{~cm}$ below the water. The latency of each aged cognitively impaired group (vehicle, NGF, or D3) was also analyzed as the average time spent in each quadrant of the pool using the same software program (HVS Image).

Memory test. At the 5th and 12th weeks after drug delivery, rats were placed in the water maze with no platform, for three trials of $60 \mathrm{sec}$ with an intertrial interval of $20 \mathrm{~min}$ in a single day. The data are expressed as percentage of time spent in each quadrant \pm SEM, the "target quadrant" being where the platform had been hidden before. This experiment is reflective of memory because there is no new learning.

\section{Surgical procedures and CNS administration}

Cognitively impaired rats were anesthetized and placed in a stereotaxic apparatus (David Kopf Instruments, Tujunga, CA). They were implanted with cannulas (Alzet) into the lateral ventricle, according to the following coordinates from bregma: anteroposterior, $-0.8 \mathrm{~mm}$; lateral, $1.3 \mathrm{~mm}$; vertical, $3.5 \mathrm{~mm}$ (Paxinos and Watson, 1986). The cannulas were connected to sterile coiled polyethylene tubing filled with an air-oil spacer (Vahlsing et al., 1989; Varon et al., 1989) at the pump end. Rats receiving control vehicle (saline group; $n=8$ ) had pumps filled with phosphate-buffered artificial CSF $\left(150 \mathrm{~mm} \mathrm{NaCl}, 1.8 \mathrm{~mm} \mathrm{CaCl}_{2}, 1.2 \mathrm{~mm}\right.$ $\mathrm{MgSO}_{4}, 2 \mathrm{mM} \mathrm{K}_{2} \mathrm{HPO}_{4}, 10 \mathrm{~mm}$ glucose, and $0.001 \%$ rat serum, $\mathrm{pH} 7.4$ ). Rats receiving positive control (NGF group; $n=7$ ) had $1.4 \mu \mathrm{g} / \mathrm{d}$ of $2.5 \mathrm{~S}$ NGF (Cedarlane Laboratories, Ontario, Canada) diluted in saline vehicle (a total of $\sim 20 \mu \mathrm{g}$ NGF). This concentration of NGF was established previously to be neuroprotective in dose-response studies in vivo (Garofalo and Cuello, 1995). Rats receiving test peptidomimetic (D3 group; 

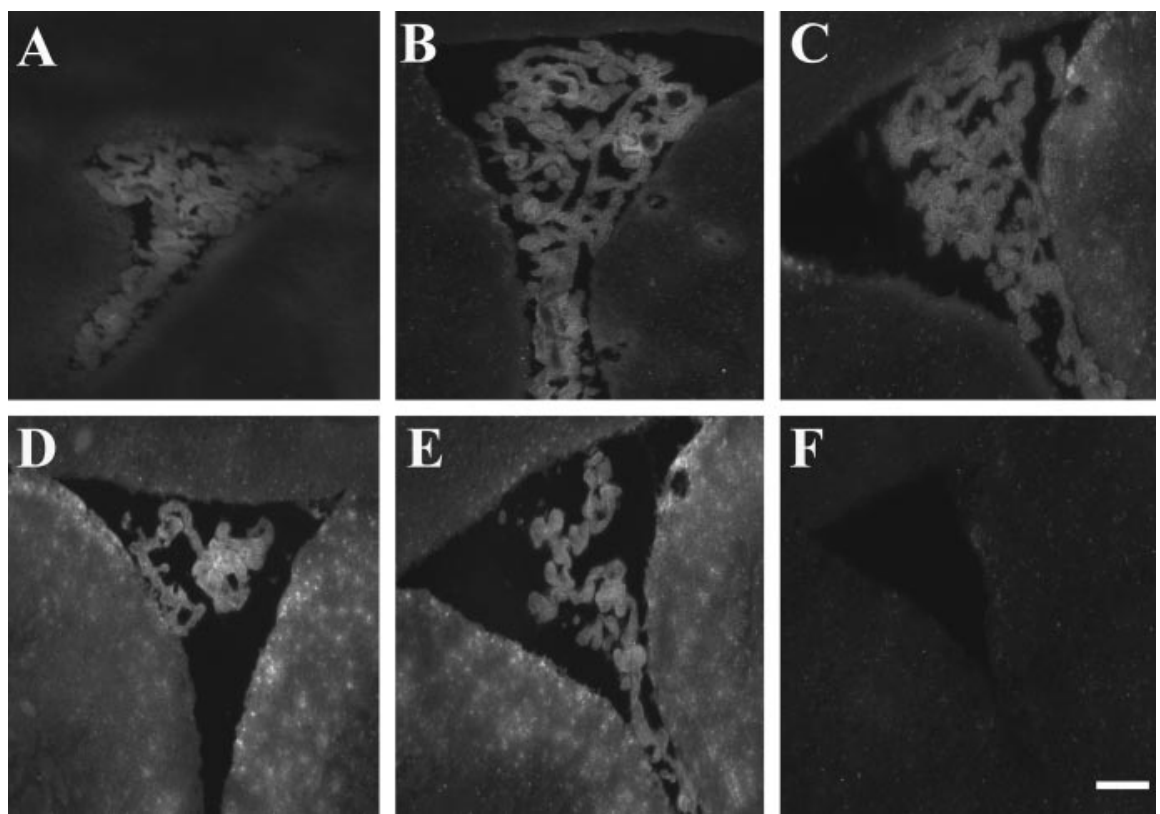

Figure 1. Peptidomimetic D3 efficiently penetrates the CNS parenchyma. Images of the lateral ventricle of fresh, unfixed tissue after D3-biotin injection at time points: $15 \mathrm{~min}(A) ; 2 \mathrm{hr}(B) ; 4 \mathrm{hr}(C) ; 8 \mathrm{hr}(D) ; 12 \mathrm{hr}(E) ; 24 \mathrm{hr}(F)$. At $2 \mathrm{hr}$ after injection, D3-biotin started to penetrate the CNS parenchyma and gave a maximal signal at the 8 and $12 \mathrm{hr}$. At $24 \mathrm{hr}$, no D3-biotin is apparent in the choroid plexus or ventricular surface. Scale bar, $200 \mu \mathrm{m}$.

$n=7$ ) had $2.8 \mu \mathrm{g} / \mathrm{d}$ D3 diluted in saline vehicle (a total of $\sim 40 \mu \mathrm{g}$ of D3). This concentration of D3 was chosen based on its potency and affinity relative to NGF. The tubing was connected from its oil spacer end to Alzet 2002 ( $14 \mathrm{~d}$ life span) osmotic minipumps filled with dye ( $0.1 \%$ methylene blue), which were pretested to confirm their delivery rates. After the end of the drug delivery, the pump placed subcutaneously in the neck/shoulder area and the tubing were removed from anesthetized rats, and the total infusion volume was determined for each animal to confirm the dosage administered. Animals were allowed to rest for 1 week, and the testing phase of the memory task was performed as described above.

\section{Phenotypic analyses}

After completion of the behavioral studies, rats were anesthetized and perfused transcardially with a mixture of $4 \%$ paraformaldehyde, $0.5 \%$ glutaraldehyde, and $15 \%$ saturated picric acid in $0.1 \mathrm{M}$ phosphate buffer (PB), $\mathrm{pH} 7.4$, for $30 \mathrm{~min}$, followed by the same fixative without glutaraldehyde for an additional $30 \mathrm{~min}$. The tissue was subsequently postfixed for $4 \mathrm{hr}$ in the latter fixative mixture and left at $4^{\circ} \mathrm{C}$ with a solution of $30 \%$ sucrose in $0.1 \mathrm{~m}$ PBS. Then, $35-\mu \mathrm{m}$-thick sections between coordinates from bregma $(0.5 \mathrm{~mm}$ and $-3.0 \mathrm{~mm}$, which comprise the parietal region of the cerebral cortex and the nucleus basalis area) (Paxinos and Watson, 1986) were cut using a sledge microtome (Sliding Microtome, SM2000 R; Leica Microsystems, Quebec, Canada) equipped with a freezing stage. After rinsing in PBS, the free-floating sections were incubated for $1 \mathrm{hr}$ in a solution containing $1 \%$ bovine serum and $10 \%$ normal goat serum in $\mathrm{PB}$. Sections were then incubated overnight at $4^{\circ} \mathrm{C}$ with an anti- vesicular acetylcholine transporter (VAChT) antibody (1:10,000; a gift from Dr. R. Edwards, University of California-San Francisco, San Francisco, CA) or anti-synaptophysin antibody (1:200) (Gilmor et al., 1996) as described. After washing, the tissue was incubated in biotinylated goat anti-rabbit antibody (1:800; $2 \mathrm{hr}$ at room temperature; Vector Laboratories). After several washes, the tissue was incubated in $0.6 \%$ diaminobenzidine (Sigma) in Tween 20 in PBS (15 min at room temperature). Subsequently, $\mathrm{H}_{2} \mathrm{O}_{2}$ was added to the diaminobenzidine solution. After washing, the sections were mounted on gelatin-coated glass slides and were dehydrated and coverslipped with Entellan (Merck, Darmstadt, Germany). Omission of the primary antibody served as a negative control.

\section{Image analysis}

The density of VAChT-immunoreactive (IR) or synaptophysin-IR presynaptic boutons in lamina $\mathrm{V}$ of the parietal cortex (bregma coordinates: lateral, $4.7-5.7 \mathrm{~mm}$; ventral, $3.0-4.2 \mathrm{~mm}$ ) and the size and density of the VAChT-IR neurons at the nucleus basalis (lateral, $2.3-3.1 \mathrm{~mm}$; anteroposterior, -1.2 to $-1.8 \mathrm{~mm}$; ventral, $6.3-$ $7.3 \mathrm{~mm}$ ) per $1000 \mu \mathrm{m}^{2}$ were measured using a BH-2 Olympus microscope connected to an image analysis system (MCID Elite; Imaging Research, St. Catharines, Ontario, Canada) as described (Debeir et al., 1999). Briefly, five images per area, from both hemispheres, were taken from five different slices per rat (50 images per rats for each region basalis and cortex) For lamina $\mathrm{V}$ of the parietal cortex and the nucleus basalis, five animals were used in each group: young adult, aged unimpaired, aged impaired, aged impaired plus saline, and aged impaired plus D3. For the NGF group, 4 animals were analyzed. Because our previous studies have shown that sham surgeries (no infusion of saline control) on mature or in aged rats have no impact on behavior or basal forebrain cholinergic markers (Garofalo and Cuello, 1994, 1995; Garofalo, 1995), we opted to forgo these additional surgical controls. For quantification of lamina $\mathrm{V}$ of the parietal cortex, a total area of $80,000 \mu \mathrm{m}^{2}$ were analyzed per rat. For the nucleus basalis, a total of 50,000 $\mu \mathrm{m}^{2}$ were analyzed per rat. Results are expressed per 1000 $\mu \mathrm{m}^{2}$. For analyses of cell size, a total of 10,000 VAChT-IR cells per rat were studied.

Preparation of $\mathrm{D} 3$ and NGF

D3 and D3-biotin were prepared as described (Maliartchouk et al., 2000). The material was analyzed as homogeneous single peak by analytical HPLC, by matrix-assisted desorption ionization mass spectrometry, and by ${ }^{1} \mathrm{H}$ NMR (300 MHz; DMSO- ${ }_{6}$ ) (Pattarawarapan and Burgess, 2000; Pattarawarapan et al., 2002), and the expected structure was confirmed. D3 was prepared in saline buffer at $\sim 3.5 \mathrm{mg} / \mathrm{ml}$. 2.5 S NGF (Cedarlane Laboratories, Ontario, Canada) was prepared in saline buffer.

\section{Data analysis}

Statistical analyses were performed using commercial software (Systat 10.0; SPSS Inc., Chicago, IL). Data were subjected to univariate and multivariate ANOVA; for repeated measures, the Huyhn-Feldt $p$ value is reported. Between-group comparisons were made using Tukey's test. All probability values were two-tailed; a level of $5 \%$ was considered significant. Data are reported as the mean \pm SEM.

\section{Results}

The D3 peptidomimetic TrkA ligand distributes throughout the CNS parenchyma and colocalizes with the TrkA receptor D3-biotin was given intracerebroventricularly to assess whether small peptidomimetics penetrate the CNS parenchyma efficiently. After an intracerebroventricular injection of D3-biotin $(10 \mu \mathrm{g})$, rats were killed without perfusion at times $0.25,2,4,8$, 12 , and $24 \mathrm{hr}$ and stained with mouse anti-biotin-Alexa-488 (Fig. 1). At $2 \mathrm{hr}$ (Fig. $1 \mathrm{~B}$ ) and $4 \mathrm{hr}$ (Fig. 1C) after injection, D3-biotin started to penetrate the CNS parenchyma. A maximal signal is seen at the $8 \mathrm{hr}($ Fig. $1 \mathrm{D})$ and $12 \mathrm{hr}$ (Fig. $1 \mathrm{E}$ ) time points. At $24 \mathrm{hr}$ (Fig. $1 F$ ), no signal is apparent in the choroid plexus or ventricular surface. Hence, D3-biotin is efficient at penetrating brain parenchyma.

More detailed colocalization studies were performed using D3-biotin and subjecting the rats to a perfusion-fixation step to remove unbound D3-biotin $24 \mathrm{hr}$ after injection (Fig. 2). Most of the D3-biotin was washed off by perfusion, and it is presumed that those D3-biotin molecules were not bound to a receptor. Specific analyses of target areas where TrkA is expressed (e.g., 
cerebral cortex and nucleus basalis) revealed bound D3-biotin remaining after perfusion and could not be washed off, suggesting that it is tightly bound to a receptor. These D3-biotin molecules accumulated at the cell surface of lamina $\mathrm{V}$ parietal cortical neurons, the nuclei of which were identified with the NeuN marker (Fig. 2A). Additional analysis using glial markers demonstrated no colocalization of D3-biotin signal with GFAP in parietal cortex lamina V (Fig. 2 B). Finally, studies in the nucleus basalis demonstrated colocalization of the D3-biotin signal with TrkA immunoreactivity (Fig. 2C). Together, these data indicate that $\mathrm{D} 3$ binds to cell surface TrkA expressed in neurons.

\section{Preselection of aged, cognitively impaired rats}

An aged rat model of cognitive impairment was used to test in vivo the TrkA partial agonist D3 (Fig. 3A). From of a pool of 120 aged rats (24-month-old males), the Morris water maze allowed preselection of 31 rats that were severely cognitively impaired (Fig. 3B). In the Morris water maze rats, use visual clues to learn and recall the position of a platform hidden underwater. Visual impairment was ruled out as the cause of poor performance by testing with the platform exposed (Fig. 3B) (day 6).

All data were analyzed for swim speed to rule out motor deficits. Thirty-one cognitively impaired aged rats were thus selected. In the visual platform task (Fig. $3 B$ ) (day 6 ), latencies to reach the platform were low in all three groups. However, Tukey's test revealed significant between-group differences $(p<0.05$ to $p<0.0001)$ in which young animals tended to reach the platform soonest and the aged impaired last. This difference may be attributable to swim speed because this measure differed between the three groups of animals $(F=37.1$; df 2, 57; $p<0.0001)$. This group difference did not differ across days (day $\times$ group interaction: $F=1.1$; df 8,$228 ; p>0.3$ ), and the young animals swam fastest $(22.3 \pm 0.5 \mathrm{~cm} / \mathrm{sec})$.

Importantly, the swim speed of the two aged groups (unimpaired and impaired) were indistinguishable (18.7 \pm 0.1 and $18.7 \pm 0.2$, respectively). Therefore, swim speed did not account for poor performance in the aged rats. Additionally, poor performance by cognitively impaired aged rats was not attributable to thigmotaxis, which is a tendency of the animal to swim in contact with the pool wall (Graziano et al., 2003). All rats (young, aged unimpaired, aged impaired) swam in each zone (Fig. 3C) for a similar relative amount of time (Fig. 3D). Therefore, thigmotaxis did not account for poor performance in the aged impaired rats.

Thus, 31 aged cognitively impaired rats were defined and selected. Of these 31, two died of natural causes. Of the remaining 29 aged cognitively impaired rats, 24 were used for drug testing, followed by behavioral analyses (see Figs. 4, 5) and studies of the cholinergic phenotype (see Figs. 6, 7). The remaining five aged cognitively impaired rats (together with five aged unimpaired rats and five young adult rats) were used as controls for analyses of the density of presynaptic cholinergic boutons in the parietal cortex, and the density and size of cholinergic neurons in the nucleus basalis in rats not exposed to drugs (see Figs. 6, 7).

\section{The peptidomimetic TrkA ligand, D3, affords rescue} of age-associated cognitive deficits in vivo

Twenty-four cognitively impaired aged rats were randomly allocated to three treatments. One group received vehicle (saline; $n=$ $8)$, another received NGF-positive control $(n=8)$, and another received D3 $(n=8)$. Over $14 \mathrm{~d}$, a total of $\sim 20 \mu \mathrm{g}$ of NGF was administered, a dose previously shown to be neuroprotective (Garofalo and Cuello, 1995). Over $14 \mathrm{~d}$, a total of $\sim 40 \mu \mathrm{g}$ of D3 was administered, a dose chosen from previous pilot studies with aged rats (data not shown) reflecting the lower ex vivo TrkA binding affinity and efficacy of D3 compared with NGF. On week 4 after initiation of drug delivery, rats were retested for learning and memory in the Morris water maze, as shown in the experimental flowchart of Figure 4. All rats in the saline and the D3 groups survived surgery and testing with no signs of side effects. In the NGF group, there were two rats with tremors and weight loss (a known side effect of applying NGF therapeutically). All the Morris water maze testing data from these two rats in the NGF group were completely discarded. Also, there were two deaths each in the NGF and the D3 groups attributable to natural causes. Thus, the $n$ values were $n=8$ (vehicle), $n=6$ (D3), and $n=4$ (NGF).

Rats that received D3 or NGF had significantly improved performance compared with the saline group from trial 2 onward of the testing phase (Fig. 4A). However, NGF and D3 were not significantly different from each other. Swim speeds of aged impaired animals receiving treatments were not a factor because they were closely similar between groups and across trials. The 
A.
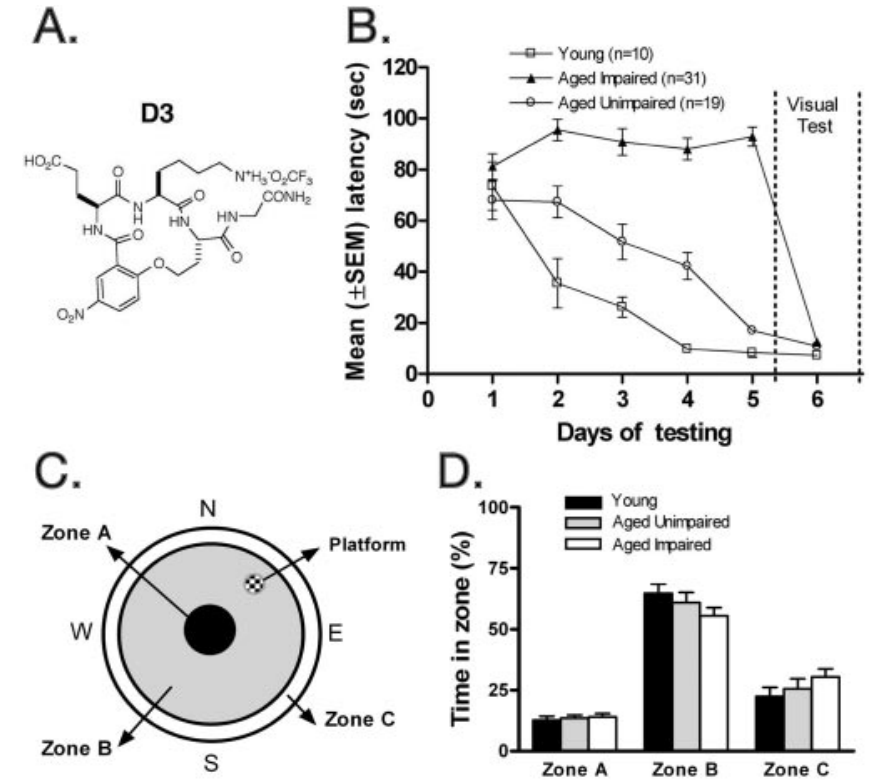

D.

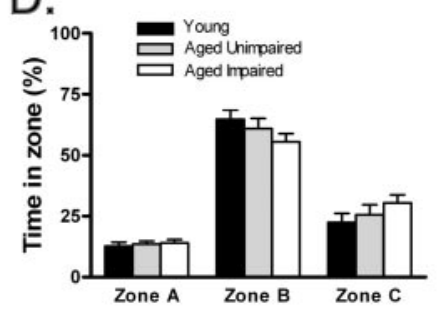

Figure 3. Preselection of cognitively impaired aged rats. $A$, TrkA partial agonist $D 3$ peptidomimetic. $B$, Segregation of cohorts of aged impaired rats in the Morris water maze (see Materials and Methods for details). Latency scores were subjected to a two-way ANOVA with two factors: days (within-subject) and group (between-subject). This confirmed that the three groups did indeed differ. The main effects of day and group, and their interaction, were all highly significant $(F=99.0 ; \mathrm{df} 2,228 ; p<0.0001 ; F=18.1 ; \mathrm{df} 4,228 ; p<0.0001 ; F=10.3 ; \mathrm{df} 8,228 ; p<$ 0.0001 , respectively). In the visual platform task (day 6 ), all three groups reached the platform rapidly. C, Graphic representation of the pool divided into three concentric zones (Zone A, $20 \mathrm{~cm}$ diameter; Zone B, $45 \mathrm{~cm}$ width; Zone $C, 15 \mathrm{~cm}$ from the outer wall). The location of the escape platform is indicated in the northeast, with its center $45 \mathrm{~cm}$ from the outer wall. D, The young, aged unimpaired, and aged impaired groups spend similar relative amounts of time in the three zones averaged for days $2-5$ of the acquisition phase. In particular, there was no group difference in the proportion of time spent in the outer Zone $C$, which is a measure of thigmotaxis $(F=$ $0.99 ; \mathrm{df} 2.57 ; p>0.3)$.

mean swim speeds (centimeters per second) for the vehicle, D3, and NGF groups were, respectively, $18.2 \pm 0.2,18.2 \pm 0.2$, and $18.1 \pm 0.2$ (ANOVA main effects and interaction; $p>0.7$ ).

The data in Figure $4 \mathrm{~A}$ were further evaluated by quadrant analyses, specifically comparing trial 1 and trial 7 on week 4 postdrug delivery. The data are presented as the percentage of time the animals spend in the trained quadrant (where the platform is located) versus the other three quadrants (Fig. $4 B$ ). The analyses for the vehicle, NGF, and D3 groups are shown for trial 1 (Fig. 4C) and trial 7 (Fig. 4D). As expected, in trial 1, there were no significant differences among the vehicle, NGF, or D3 groups (Fig. 4C), but in trial 7, the NGF and the D3 groups had a significant improvement at targeting the trained quadrant compared with vehicle (Fig. 4D). Tukey's test showed that this measure differed significantly between groups on trial 7 but not on trial 1 (ANOVA; $p<0.0001$ and $p>0.09$, respectively). In trial 7 , comparisons for all three groups were significant $(p<0.05$ to $p<0.0001)$. These results are suggestive of improved learning and/or memory by the NGF and D3 groups.

\section{D3 affords a long-lasting rescue of age-associated memory deficits in vivo}

To discriminate between learning and memory, the rats were tested in the same pool for a fixed time of $1 \mathrm{~min}$, but without the hidden platform, thus offering no escape and no new learning. Because there is no successful resolution of the task, because there is no platform to find, the time spent in the target quadrant (where the platform had been placed) does not reflect new learning but only memory.

Representative swim paths from individual rats at 12 weeks after drug delivery are shown in Figure 5A. The NGF and the D3 groups spent a significantly higher proportion of time in the target quadrant at week 5 (Fig. 5B) and week 12 (Fig. 5C) after drug delivery. In contrast, saline-treated rats spent very similar amounts of time in each quadrant (Fig. $5 B, C$ ). These data indicate that the behavioral improvement afforded by D3 and NGF is very long-lived and attributable, at least in part, to improved memory.

\section{D3 rescues the cholinergic neuronal phenotype in vivo}

All the aged rats used for behavioral testing were killed 12 weeks after drug delivery, their brains were perfused and fixed, and multiple serial cryosections were prepared. As controls, an additional cohort not subjected to drug treatment or surgery (five young rats, five aged unimpaired rats, and five aged impaired rats) were studied as well. Sections were immunostained with antibodies to VAChT. This marker was chosen because cortical changes in VAChT accompany age-dependent cognitive impairments in mammals (Bartus et al., 1982; Hasselmo, 1999; Turrini et al., 2001; Casu et al., 2002). The density of VAChT-IR presynaptic boutons in the lamina $\mathrm{V}$ of the parietal cortex and the size of soma in the nucleus basalis were studied quantitatively. Concomitant analyses of synaptophysin immunostaining and density were also done to test for cholinergic specificity.

In untreated rats, computer-assisted image analysis of the number of VAChT-IR boutons in lamina V of the parietal cortex demonstrated a reduction in cognitively impaired aged rats compared with young rats $(p<0.001)$ and between cognitively impaired aged rats and unimpaired aged rats $(p<0.01)$. There were no statistical differences between the young rats and unimpaired aged rats (Fig. 6A).

In cognitively impaired aged rats, treatment with D3 or NGF significantly ( $p \leq 0.001$ ) increased the density of cortical cholinergic (i.e., VAChT-IR) presynaptic boutons to a similar extent, $\sim 40 \%$ (Fig. $6 \mathrm{~A}$ ). It is noteworthy that the phenotypic changes in forebrain VAChT expression brought about by D3 and NGF treatments were long-lived and lasted up to 12 weeks after drug treatment.

Control immunostaining of all cortical presynaptic sites with synaptophysin antibodies in adjacent serial sections demonstrated no variation in that marker (Fig. $6 B$ ), except a slight difference between the young and aged impaired groups $(p<0.05)$. This control indicates that D3 is a fairly selective agent for NGFsensitive cholinergic neurons. The microscopic appearance of images of VAChT cortical presynaptic sites is shown to illustrate the VAChT changes in each of the test groups (Fig. 6C).

The size of VAChT-immunostained cell somata in the nucleus basalis was determined by computer-assisted image analysis. In untreated rats, mean somal size was significantly $(p<0.01)$ reduced in cognitively impaired aged rats compared with young rats (Fig. $7 A$ ). There was a small but significant difference between unimpaired aged rats compared with impaired aged rats $(p<0.05)$, but not between young rats and unimpaired aged rats.

In cognitively impaired aged rats, treatment with either D3 or NGF increased significantly $(p<0.001)$ the somal size of nucleus basalis neurons by $\sim 30 \%$ (Fig. $7 A$ ). Because the size of D3- or NGF-treated rats was not significantly different from each other or from young rats, the data would suggest that drug treatment reversed shrinkage. As was the case with cholinergic terminals, 
Preselected Cognitively Impaired Aged Rats

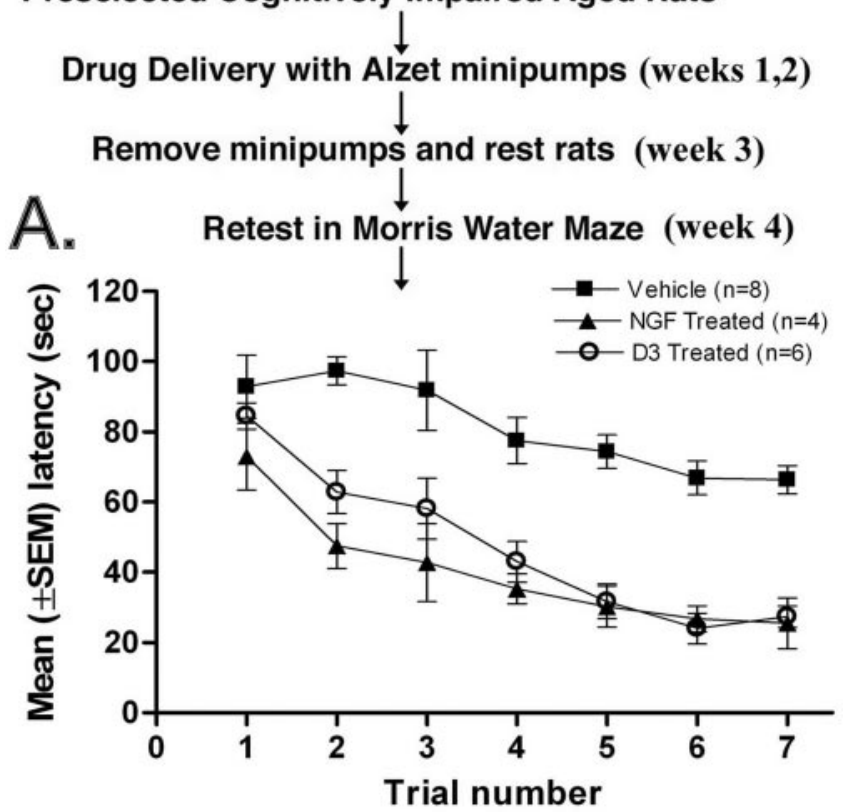

B.
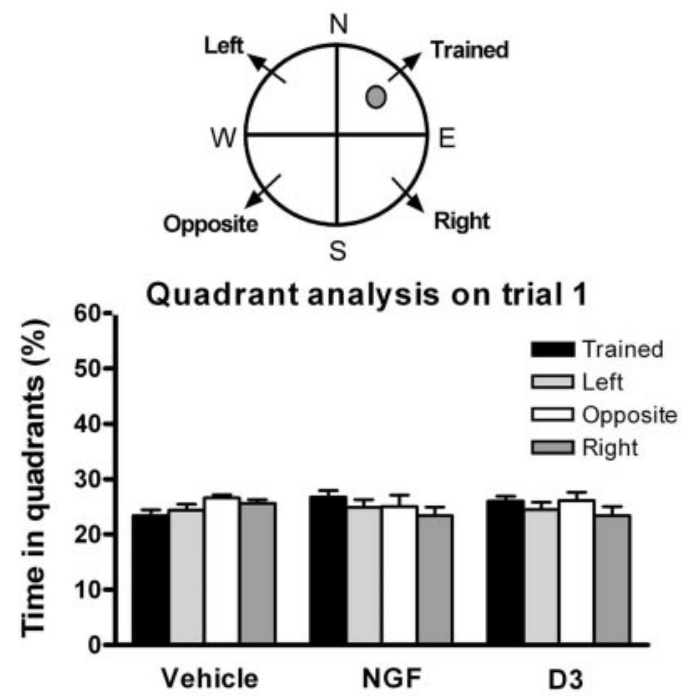

D.

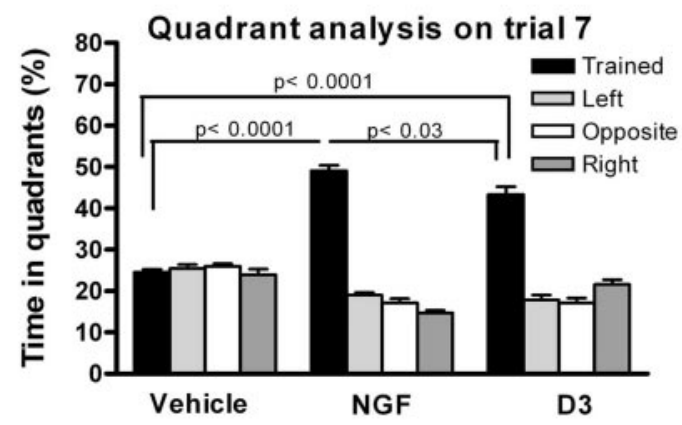

Figure 4. D3 and NGF improve performance in cognitively impaired aged rats. A, Cognitively impaired rats were treated as indicated and then were retested, as described in Materials and Methods, in the Morris water maze on week 4 after initiation of drug delivery. ANOVA of latencies to find the platform revealed significant main effects of group $(F=44.8 ; \mathrm{df}=2,15 ; p<$ $0.0001)$ and trial $(F=18.6 ; \mathrm{df}=6,90 ; p<0.0001)$. The latencies of D3- and NGF-treated rats were similar in all trials, whereas both groups diverged significantly from the vehicle-treated control group (group $X$ linear trend of trial: $F=4.62 ; \mathrm{df}=2,15 ; p<0.05$ ). Drug effects were evident, for example, for data pooled across the last four trials (Tukey's test: D3 or NGF vs vehicle, $p<0.0001$ ). $B$, Schematic graph of the pool showing the quadrants and the position of the submerged escape platform. Data for Figure $4 A$ were evaluated by quadrant analyses and the phenotypic changes in cell somata brought about by D3 and NGF were long-lived because they lasted up to 12 weeks after drug treatment. There were no significant changes observed in the density of nucleus basalis cholinergic cell bodies (Fig. $7 B$ ), thus reinforcing the notion that atrophy (rather than cholinergic forebrain cell loss) is a feature in age-related cholinergic decline.

\section{Discussion}

We demonstrated the biological actions and usefulness of a peptidomimetic small molecule TrkA agonist named D3 (Maliartchouk et al., 2000) in an in vivo model of cognitive impairment. D3 affords a significant, long-lasting, and selective enhancement of the CNS cholinergic phenotype in cognitively impaired aged rats, accompanied with a significant, long-lasting improvement in the cognitive ability of aged rats thus treated. In these investigations, D3 and NGF afforded comparable results at the doses tested.

Targeting TrkA in cognitive disorders

In the normal adult human CNS, the cortical and nucleus basalis neurons that comprise the cholinergic system participate in higher brain functions such as learning and memory. These neurons express the TrkA receptor (Mufson et al., 1997) and are responsive to NGF. In neurodegenerative processes such as mild cognitive impairment (MCI), loss of TrkA density correlates with neuronal atrophy and precedes neuronal death and severe cognitive impairment in $\mathrm{AD}$ (Counts et al., 2004). Indeed, in MCI-AD progression, and in Down's syndrome, loss of TrkA correlates with cognitive decline (Mufson et al., 2000, 2002). Likewise, in basal forebrain neurons of the aged rat, there is reduced expression of NGF receptors, which is reversed by delivery of NGF (Backman et al., 1997).

Although published evidence linking a compromised TrkANGF system and progressive cognitive impairment is substantial, consistent for many models (MCI, AD, aging, and Down's syndrome), and NGF reverts cognitive impairment, the relationship seems to be casual rather than causal. Additional studies will be needed to address causality.

\section{Selective improvement to cognition and the} cholinergic system

We demonstrate that the age-dependent cognitive impairment is accompanied by marked cholinergic synaptic loss, reduction in the size of cholinergic cell soma (but not in cell numbers), and by reduced expression of VAChT. These behavioral and phenotypic deficits are reverted by NGF and D3. The pharmacological effects are long lasting and were observed for 3 months after the initiation of drug treatment. It is gratifying that our data using exogenous NGF as control is consistent with previous reports (Fischer et al., 1987; Chen et al., 1995).

The in vivo cholinergic selectivity of $\mathrm{D} 3$ was evidenced by a specific enhancement of VAChT-IR boutons, but an absence of an effect on the overall presynaptic population (e.g., synaptophysin-IR boutons), and was anticipated because D3 is a TrkA ligand.

One interesting finding corollary to our study of D3 provides additional confirmation that structural changes (reduced density of VAChT-IR presynaptic boutons in the neocortex and smaller

presented as the percentage of time spent in the trained quadrant (where the platform is located) versus the other three quadrants. C, Analyses for the vehicle, NGF, and D3 groups for trial 1. D, Analyses for the vehicle, NGF, and D3 groups for trial 7. Statistical comparisons refer to Tukey's test. 
A.

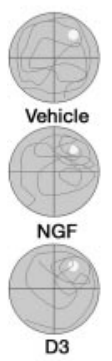

B.

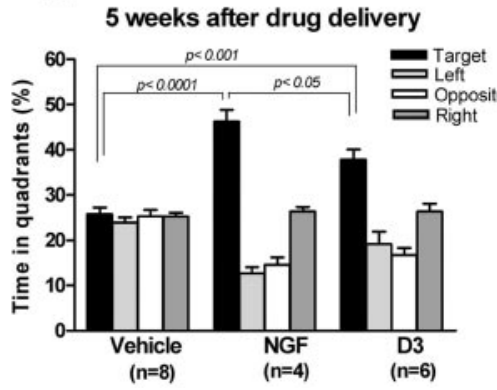

C.

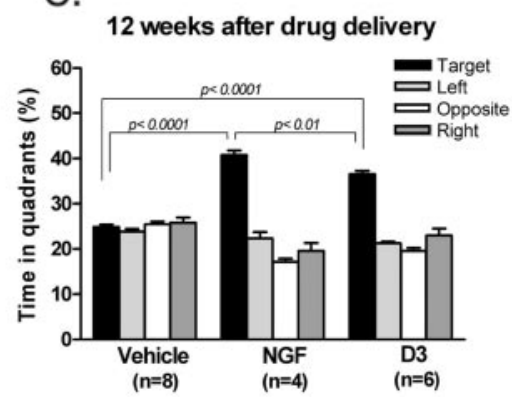

the cytoplasma or inside neurite extensions. There are five possible explanations for these differences.

First, there may be lower relative signal intensity for D3 versus anti-TrkA serum because the latter has multiple reactivities. Second, the TrkA protein present in neurite terminals (seen with anti-TrkA serum after fixation/permeabilization) may be mostly intracellular and not cell surfaced, and hence it is not accessible to the D3biotin injected in vivo. Third, relative receptor density in the neurites may be lower than in the cell somata. Fourth, intracellular retrogradely transported D3 may be processed (i.e., the biotin label is cleaved off) and becomes undetectable. Fifth, perhaps the D3-TrkA complex does

size of somata in the nucleus basalis) may be directly implicated in aged-associated cognitive decline because such changes occur only in the cognitively impaired aged rats but not in the unimpaired aged rats.

Our results suggest that it may be possible to delay the chronic and progressive cholinergic neurodegeneration in aging or in pathological states with the use of neurotrophin receptor agonists. If selective agonists of TrkA were to be applied before extensive CNS damage (e.g., in MCI), it is conceivable that selective protection of cholinergic forebrain neurons and cognitive improvements could be achieved. Additionally, single or concomitant use of pharmacological modulators of p75 action or potentiators of NGF activity may also prove to be useful (Maliartchouk and Saragovi, 1997; Saragovi and Burgess, 1999; Saragovi and Maliartchouk, 1999).

To our knowledge, D3 is the first reported small molecule ligand capable of inducing selective survival of the cholinergic neurons. Other small molecules with drug-like properties, such as GM1 or the immunophilins, have been nonselective (Saragovi and Burgess, 1999; Saragovi and Gehring, 2000).

\section{Efficacy and selectivity}

Selectivity, rather than potency or affinity, is the most relevant feature that impacts on drug efficacy in vivo (Mattie et al., 1989; Troke et al., 1990; Brook, 1991; Vella and Floridia, 1998; Waldman, 2002). For example, despite its high TrkA binding affinity $\left(K_{\mathrm{d}}, 10-100 \mathrm{pM}\right), \mathrm{NGF}$ has a narrow therapeutic window partly because of poor selectivity (e.g., it binds p75 receptors), partly because of pleiotropic activation, and partly because of a short half-life. In contrast, the TrkA binding affinity of D3 is $\sim 5 \mu \mathrm{M}$. However, D3 does not bind another target, and it does not activate other Trk receptors (Maliartchouk et al., 2000). Therefore, D3 may afford a large therapeutic window.

D3 can be detected associated with TrkA receptors for a relatively long time (as shown in Fig. 2C). Improved penetration and stability for D3 (compared with NGF) may result in better access to target tissue from the site of administration.

\section{Targeting TrkA in vivo}

Anti-TrkA antiserum revealed TrkA protein in four spatial locations: at the surface of the cell soma and the neuritic terminals and intracellularly at the cytoplasma and the neurites. In contrast, we noted that $\mathrm{D} 3$ seems to localize preferentially at TrkA receptors present on the cell surface of the somata. There is very little D3 on the cell surface of neuritic terminals or inside cells either at not internalize efficiently. In vitro studies of neuronal cultures documented that ligand-activated TrkA neurotrophic signals do not require internalization of the NGF-TrkA complex (Neet and Campenot, 2001); thus, our in vivo studies would be compatible with those results.

\section{Pharmacological advantages}

Two properties of D3 are desirable in a drug candidate: proteolytic stability and no incidence of side effects compared with NGF. The ex vivo proteolytic stability of D3 has been shown previously (Maliartchouk et al., 2000). D3 is extremely stable to pepsin, chymotrypsin, papain, trypsin, and other peptidases. Preliminary pharmacokinetic studies on D3 (data not shown) showed a serum half-life of $\sim 4.5 \mathrm{hr}$ and the appearance of two metabolites. In contrast, the serum half-life of NGF is in the order of minutes (Verrall, 1994).

The effective dose of NGF (nearly the lowest effective dose identified in published reports) (Garofalo and Cuello, 1995) caused noteworthy weight loss and tremors as side effects in two of eight (25\%) of the tested rats. In contrast, the effective dose of D3 did not appear to cause these side effects or any obvious signs of toxicity, but we have not performed objective pathological studies. Note that all the data with NGF toxemic rats were discarded. Had that data been considered, the neuroprotective and behavioral effect of D3 would have been significantly better than NGF.

Although D3 is a partial agonist of TrkA, its intrinsic activity is relatively low and it is best revealed when acting as a synergistic potentiator of NGF (Maliartchouk et al., 2000). This property may be advantageous when testing in vivo because, in some neurogenerative disorders, NGF protein is increased (Fahnestock et al., 1996; Hock et al., 2000a,b); but this NGF protein is either less active or has different activity (Fahnestock et al., 2004a,b). For that reason, a selective small molecule NGF potentiator such as D3 may be extremely effective.

Also, D3 binds at the IgC2 ectodomain of TrkA, which is defined as a functional "receptor hot spot." In contrast, NGF seems to bind at least two hot spots on TrkA (Zaccaro et al., 2001; Saragovi and Zaccaro, 2002). A potentially attractive feature is that small molecules could target receptors at single, defined, activation, or regulatory hot spots (e.g., only the $\mathrm{Trk} \operatorname{IgC} 2$ ectodomain) while excluding coreceptors (e.g., p75 receptors). Thus, binding to a single receptor site could afford partial receptor activation and higher selectivity. 

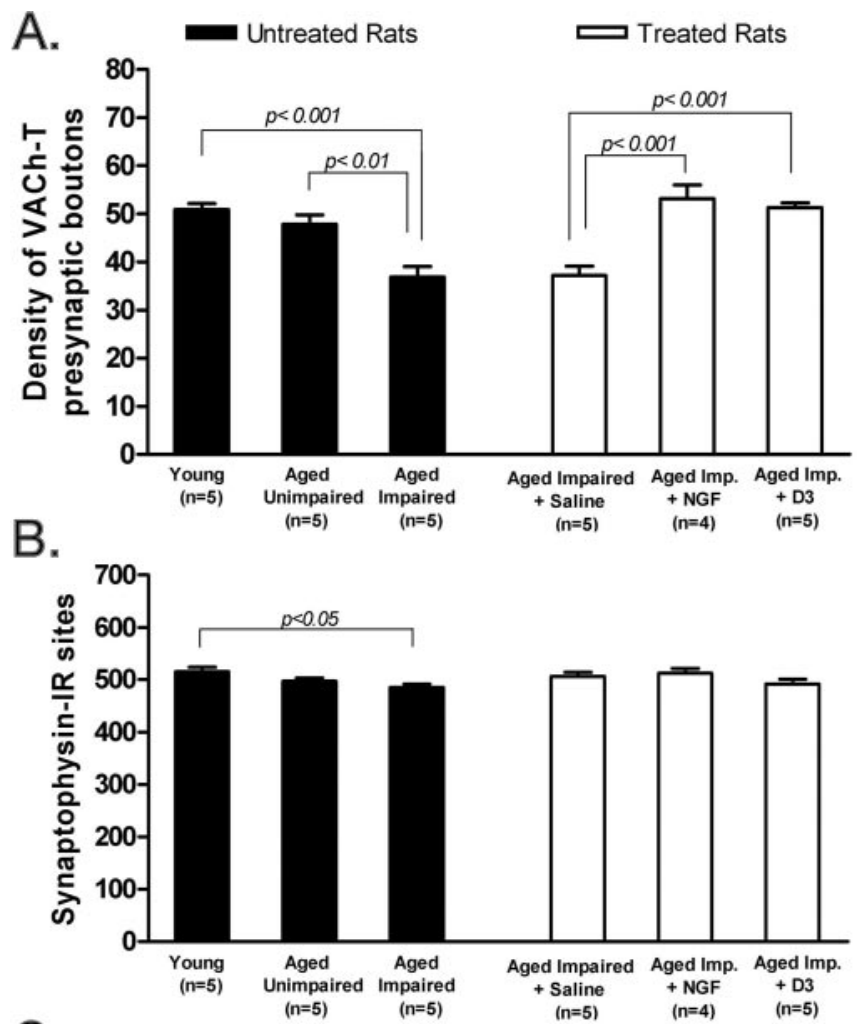

C.
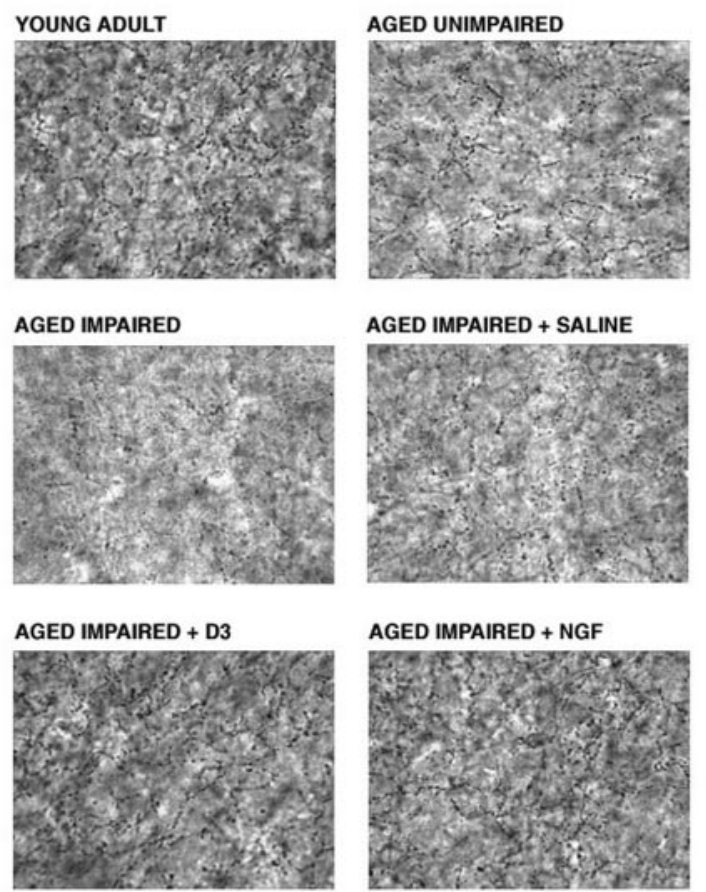

Figure 6. Selective effect of $\mathrm{D} 3$ on the cholinergic phenotype of cortical neurons. $A$, Number (boutons/1000 $\mathrm{m}^{2}$ ) \pm SEM of cholinergic presynaptic boutons (VAChT immunoreactive). $B$, Total presynaptic boutons (synaptophysin immunoreactive) in lamina $V$ of the parietal cortex of aged Fischer-344 rats. In $A$ and $B$, a total area of $80,000 \mu \mathrm{m}^{2}$ was analyzed per rat ( $n=4$ or 5). Aged impaired versus aged impaired plus vehicle were not different from each other but presented a significantly decreased number of cholinergic presynaptic boutons versus young. Restoration of the size in the cholinergic presynaptic boutons in aged impaired plus NGF and aged impaired plus D3 when compared with aged impaired and aged impaired plus vehicle is shown. For synaptophysin staining, there were no significant differences between any groups. C, Representative pictures of lamina $V$ of the parietal cortex immunostained with anti-VAChT antibodies. Statistical comparisons refer to Tukey's test.
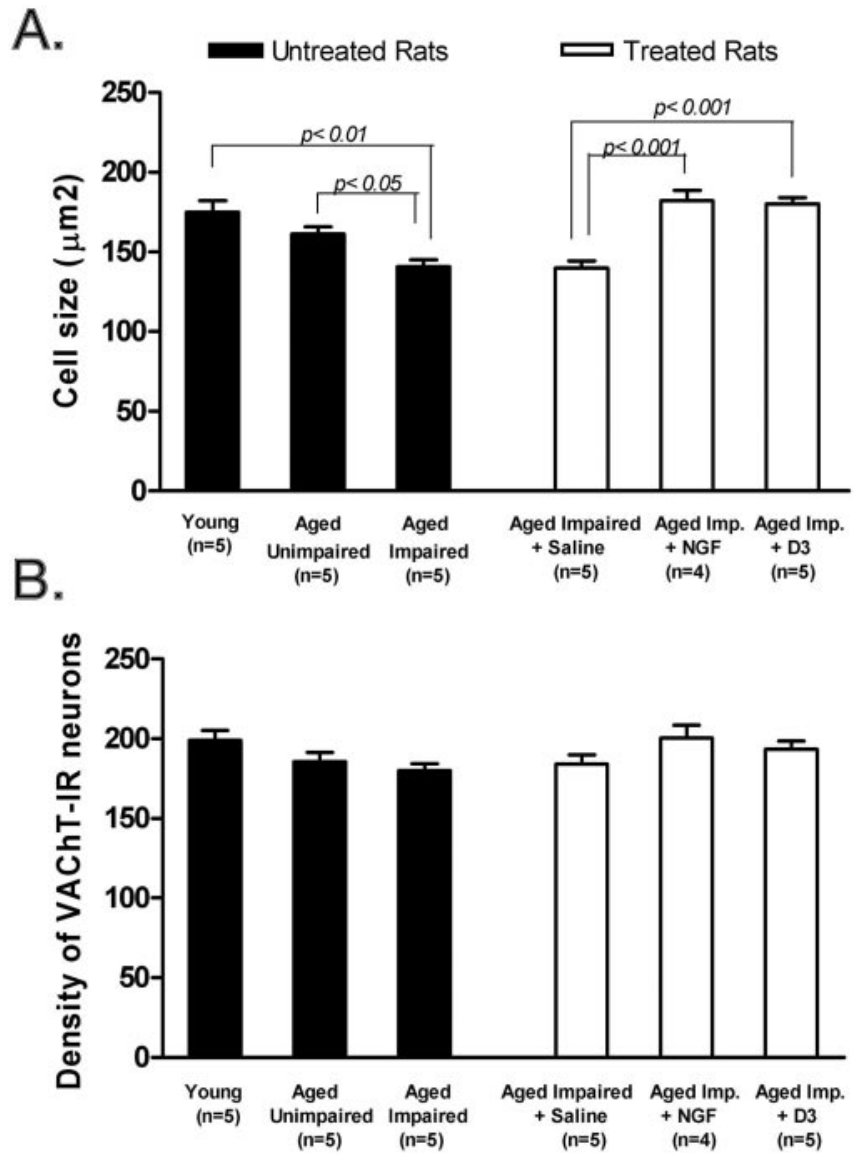

Figure 7. Selective effect of D3 on the size and cholinergic phenotype of nucleus basalis neurons. $A$, Cell size of the soma $\left(\mu \mathrm{m}^{2}\right) \pm$ SEM of VAChT-IR cholinergic neurons in the nucleus basalis of Fischer-344 rats. For cell size analyses, a total of 10,000 VachT-positive cells per rat ( $n=4$ or 5 ) were studied. Aged impaired and aged impaired plus vehicle were not different from each other but displayed significantly lower cell size than young. Restoration of the cell size of cholinergic neurons after receiving either D3 or NGF when compared with aged impaired and aged impaired plus vehicle. $B$, Density of VAChT-IR neurons, representative of neuronal numbers in the nucleus basalis. Statistical comparisons refer to Tukey's test. For VAChT density, a total of 50,000 VachT-positive cells per rat ( $n=4$ or 5 ) were studied, and data are expressed per $1000 \mu \mathrm{m}^{2}$

\section{Summary}

Disregulation of the neurotrophins or their receptors is relevant to human neuropathologies, including chronic or acute neurodegeneration, pain, and cancer (Eide et al., 1993; Hefti, 1994; Saragovi and Burgess, 1999; Saragovi and Gehring, 2000). Neurotrophin clinical trials have been disappointing because of in vivo instability, side effects produced by the activation of signals that were not intentionally targeted, and drawbacks inherent to proteins when used as drugs. For these reasons, small molecule peptidomimetics that have better pharmacokinetic properties may be useful therapeutics. From a drug development perspective, it may be desirable to have small molecules that uncouple trophic and neuritogenic signals (Saragovi et al., 1998; Zhang et al., 2000) because they can be selective therapeutics in conditions in which a single activity is required. For example, it may be desirable to support existing neurons from death but without inducing potentially maladapted de novo connections. To that end, we have developed a family of analogs of D3 with single activity (Saragovi and Burgess, 2001) (M. C. Zaccaro, H. B. Lee, M. Pattarawarapan, Z. Xia, A. Caron, K. Burgess, and H. U. Saragovi, unpublished observations). 
Future studies will be directed at establishing optimal drug concentration and efficacy, blood brain barrier penetration, and maximal tolerated doses for these compounds.

\section{References}

Aubert I, Rowe W, Meaney MJ, Gauthier S, Quirion R (1995) Cholinergic markers in aged cognitively impaired Long-Evans rats. Neuroscience 67:277-292.

Backman C, Rose GM, Bartus RT, Hoffer BJ, Mufson EJ, Granholm AC (1997) Carrier mediated delivery of NGF: alterations in basal forebrain neurons in aged rats revealed using antibodies against low and high affinity NGF receptors. J Comp Neurol 387:1-11.

Barinaga M (1994) Neurotrophic factors enter the clinic. Science 264:772-774.

Barker PA (1998) p75NTR: a study in contrasts. Cell Death Differ 5:346-356.

Bartus RT, Dean 3rd RL, Beer B, Lippa AS (1982) The cholinergic hypothesis of geriatric memory dysfunction. Science 217:408-414.

Brook I (1991) In vitro susceptibility vs. in vivo efficacy of various antimicrobial agents against the Bacteroides fragilis group. Rev Infect Dis 13:1170-1180.

Casu MA, Wong TP, De Koninck Y, Ribeiro-da-Silva A, Cuello AC (2002) Aging causes a preferential loss of cholinergic innervation of characterized neocortical pyramidal neurons. Cereb Cortex 12:329-337.

Chen KS, Masliah E, Mallory M, Gage FH (1995) Synaptic loss in cognitively impaired aged rats is ameliorated by chronic human nerve growth factor infusion. Neuroscience 68:19-27.

Counts SE, Nadeem M, Wuu J, Ginsberg SD, Saragovi HU, Mufson EJ (2004) Reduction of cortical TrkA but not p75NTR protein in early stage Alzheimer's disease. Ann Neurol, in press.

Debeir T, Saragovi HU, Cuello AC (1999) A nerve growth factor mimetic TrkA antagonist causes withdrawal of cortical cholinergic boutons in the adult rat. Proc Natl Acad Sci USA 96:4067-4072.

Eide FF, Lowenstein DH, Reichardt LF (1993) Neurotrophins and their receptors-current concepts and implications for neurologic disease. Exp Neurol 121:200-214.

Fahnestock M, Scott SA, Jette N, Weingartner JA, Crutcher KA (1996) Nerve growth factor mRNA and protein levels measured in the same tissue from normal and Alzheimer's disease parietal cortex. Brain Res Mol Brain Res 42:175-178.

Fahnestock M, Yu G, Coughlin MD (2004a) ProNGF: a neurotrophic or an apoptotic molecule? Prog Brain Res 146:107-110.

Fahnestock M, Yu G, Michalski B, Mathew S, Colquhoun A, Ross GM, Coughlin MD (2004b) The nerve growth factor precursor proNGF exhibits neurotrophic activity but is less active than mature nerve growth factor. J Neurochem 89:581-592.

Fischer W, Wictorin K, Bjorklund A, Williams LR, Varon S, Gage FH (1987) Amelioration of cholinergic neuron atrophy and spatial memory impairment in aged rats by nerve growth factor. Nature 329:65-68.

Frick KM, Price DL, Koliatsos VE, Markowska AL (1997) The effects of nerve growth factor on spatial recent memory in aged rats persist after discontinuation of treatment. J Neurosci 17:2543-2550.

Gage FH, Armstrong DM, Williams LR, Varon S (1988) Morphological response of axotomized septal neurons to nerve growth factor. J Comp Neurol 269:147-155.

Garofalo L (1995) Pharmacological characterization of nerve growth factor on cholinergic markers in the adult lesioned brain. $\mathrm{PhD}$ thesis, McGill University.

Garofalo L, Cuello AC (1994) Nerve growth factor and the monosialoganglioside GM1: analogous and different in vivo effects on biochemical, morphological, and behavioral parameters of adult cortically lesioned rats. Exp Neurol 125:195-217.

Garofalo L, Cuello AC (1995) Pharmacological characterization of nerve growth factor and/or monosialoganglioside GM1 effects on cholinergic markers in the adult lesioned brain. J Pharmacol Exp Ther 272:527-545.

Garofalo L, Ribeiro-da-Silva A, Cuello AC (1992) Nerve growth factorinduced synaptogenesis and hypertrophy of cortical cholinergic terminals. Proc Natl Acad Sci USA 89:2639-2643.

Gilmor ML, Nash NR, Roghani A, Edwards RH, Yi H, Hersch SM, Levey AI (1996) Expression of the putative vesicular acetylcholine transporter in rat brain and localization in cholinergic synaptic vesicles. J Neurosci 16:2179-2190.
Graziano A, Petrosini L, Bartoletti A (2003) Automatic recognition of explorative strategies in the Morris water maze. J Neurosci Methods 130:33-44

Hasselmo ME (1999) Neuromodulation: acetylcholine and memory consolidation. Trends Cogn Sci 3:351-359.

Hefti F (1994) Neurotrophic factor therapy for nervous system degenerative diseases. J Neurobiol 25:1418-1435.

Hock C, Heese K, Muller-Spahn F, Huber P, Riesen W, Nitsch RM, Otten U (2000a) Increased CSF levels of nerve growth factor in patients with Alzheimer's disease. Neurology 54:2009-2011.

Hock CH, Heese K, Olivieri G, Hulette CH, Rosenberg C, Nitsch RM, Otten U (2000b) Alterations in neurotrophins and neurotrophin receptors in Alzheimer's disease. J Neural Transm Suppl 59:171-174.

Issa AM, Rowe W, Gauthier S, Meaney MJ (1990) Hypothalamic-pituitaryadrenal activity in aged, cognitively impaired and cognitively unimpaired rats. J Neurosci 10:3247-3254

Jonhagen ME (2000) Nerve growth factor treatment in dementia. Alzheimer Dis Assoc Disord 14:S31-S38.

Kaplan DR, Miller FD (2000) Neurotrophin signal transduction in the nervous system. Curr Opin Neurobiol 10:381-391.

Lad SP, Neet KE, Mufson EJ (2003) Nerve growth factor: structure, function and therapeutic implications for Alzheimer's disease. Curr Drug Target CNS Neurol Disord 2:315-334.

Lewin GR, Barde Y-A (1996) Physiology of the neurotrophins. Annu Rev Neurosci 19:289-317.

Maliartchouk S, Saragovi HU (1997) Optimal nerve growth factor trophic signals mediated by synergy of TrkA and p75 receptor-specific ligands. J Neurosci 17:6031-6037.

Maliartchouk S, Feng Y, Ivanisevic L, Debeir T, Cuello AC, Burgess K, Saragovi HU (2000) A designed peptidomimetic agonistic ligand of TrkA NGF receptors. J Mol Pharmacol 57:385-391.

Mattie H, Craig WA, Pechere JC (1989) Determinants of efficacy and toxicity of aminoglycosides. J Antimicrob Chemother 24:281-293.

Mufson EJ, Lavine N, Jaffar S, Kordower JH, Quirion R, Saragovi HU (1997) Reduction of p140-TrkA receptor protein within the nucleus basalis and cortex in Alzheimer's disease. Exp Neurol 146:91-103.

Mufson EJ, Ma SY, Cochran EJ, Bennett DA, Beckett LA, Jaffar S, Saragovi HU, Kordower JH (2000) Loss of nucleus basalis neurons containing trkA immunoreactivity in individuals with mild cognitive impairment and early Alzheimer's disease. J Comp Neurol 427:19-30.

Mufson EJ, Ma SY, Dills J, Cochran EJ, Leurgans S, Wuu J, Bennett DA, Jaffar S, Gilmor ML, Levey AI, Kordower JH (2002) Loss of basal forebrain P75(NTR) immunoreactivity in subjects with mild cognitive impairment and Alzheimer's disease. J Comp Neurol 443:136-153.

Neet KE, Campenot RB (2001) Receptor binding, internalization, and retrograde transport of neurotrophic factors. Cell Mol Life Sci 58:1021-1035.

Pattarawarapan M, Burgess K (2000) A linker-scaffold to present dimers of pharmacophores prepared via solid phase syntheses. Angew Chem Int Ed Engl 39:4299-4301.

Pattarawarapan M, Zaccaro MC, Saragovi U, Burgess K (2002) New templates for synthesis of ring-fused $\mathrm{C}^{10} \beta$-turn peptidomimetics leading to the first reported small molecule mimic of neurotrophin-3. J Med Chem 45:4387-4390.

Paxinos G, Watson C (1986) The rat brain in stereotaxic coordinates. Sydney: Academic.

Rabizadeh S, Rabizadeh S, Ye X, Wang JJ, Bredesen DE (1999) Neurotrophin dependence mediated by p75NTR: contrast between rescue by BDNF and NGF. Cell Death Differ 6:1222-1227.

Rowe WB, O'Donnell JP, Pearson D, Rose GM, Meaney MJ, Quirion R (2003) Long-term effects of BIBN-99, a selective muscarinic M2 receptor antagonist, on improving spatial memory performance in aged cognitively impaired rats. Behav Brain Res 145:171-178.

Saragovi HU, Burgess K (1999) Small molecule and protein-based neurotrophic ligands: agonists and antagonists as therapeutic agents. Exp Opin Ther Patents 9:737-751.

Saragovi HU, Burgess K (2001) $\beta$-Turn peptidomimetic cyclic compounds. In: WO 01/52843 A1. World Intellectual Property Organization: McGill University

Saragovi HU, Gehring K (2000) Development of pharmacological agents for targeting neurotrophins and their receptors. Trends Pharmacol Sci 21:93-98.

Saragovi HU, Maliartchouk S (1999) Pharmaceutical composition with 
neurotrophic-like activity. In: WO 99074 10. World Intellectual Property Organization: McGill University.

Saragovi HU, Zaccaro MC (2002) Small molecule peptidomimetic ligands of neurotrophin receptors, identifying binding sites, activation sites and regulatory sites. Curr Pharm Des 8:2201-2216.

Saragovi U, Zheng W, Maliartchouk S, DiGugliemo GM, Mawal Y, Kamen A, Woo SB, Cuello AC, Debeir T, Neet KE (1998) A TrkA selective rapidly internalizing NGF-antibody complex induces trophic but not neuritogenic activities. J Biol Chem 273:34933-34940.

Sendera TJ, Ma SY, Jaffar S, Kozlowski PB, Kordower JH, Mawal Y, Saragovi HU, Mufson EJ (2000) Reduction in TrkA-immunoreactive neurons is not associated with an overexpression of galaninergic fibers within the nucleus basalis in Down's syndrome. J Neurochem 74:1185-1196.

Sofroniew MV, Howe CL, Mobley WC (2001) Nerve growth factor signaling, neuroprotection, and neural repair. Annu Rev Neurosci 24:1217-1281.

Thoenen H (1995) Neurotrophins and neuronal plasticity. Science 270:593-598.

Tombaugh GC, Rowe WB, Chow AR, Michael TH, Rose GM (2002) Thetafrequency synaptic potentiation in CAl in vitro distinguishes cognitively impaired from unimpaired aged Fischer 344 rats. J Neurosci 22:9932-9940.

Troke PF, Andrews RJ, Pye GW, Richardson K (1990) Fluconazole and other azoles: translation of in vitro activity to in vivo and clinical efficacy. Rev Infect Dis 12 [Suppl 3]:S276-S280.

Turrini P, Casu MA, Wong TP, De Koninck Y, Ribeiro-da-Silva A, Cuello AC
(2001) Cholinergic nerve terminals establish classical synapses in the rat cerebral cortex: synaptic pattern and age-related atrophy. Neuroscience 105:277-285.

Vahlsing HL, Varon S, Hagg T, Fass-Holmes B, Dekker A, Manley M, Manthorpe M (1989) An improved device for continuous intraventricular infusions prevents the introduction of pump-derived toxins and increases the effectiveness of NGF treatments. Exp Neurol 105:233-243.

Varon S, Hagg T, Fass B, Vahlsing L, Manthorpe M (1989) Neuronotrophic factors in cellular functional and cognitive repair of adult brain. Pharmacopsychiatry 22 [Suppl 2]:120-124.

Vella S, Floridia M (1998) Saquinavir. Clinical pharmacology and efficacy. Clin Pharmacokinet 34:189-201.

Verrall M (1994) Lay-offs follow suspension of clinical trials of protein. Nature 370:6.

Waldman SA (2002) Does potency predict clinical efficacy? Illustration through an antihistamine model. Ann Allergy Asthma Immunol 89:7-77.

Zaccaro M, Ivanisevic L, Perez P, Meakin S, Saragovi H (2001) p75 coreceptors regulate ligand-dependent and ligand-independent Trk receptor activation, in part by altering Trk docking subdomains. J Biol Chem 276:31023-31029.

Zhang Y, Moheban DB, Conway BR, Bhattacharyya A, Segal RA (2000) Cell surface Trk receptors mediate NGF-induced survival while internalized receptors regulate NGF-induced differentiation. J Neurosci 20:5671-5678. 